\title{
Taguchi Optimization In Machining Inconel 600 With WEDM Process Using Cryogenically Treated Brass Wire
}

\author{
K. Satyanarayana ${ }^{1}$, B. Ramya Krishna ${ }^{2}, M$. Bhargavi ${ }^{2}$, R. Eswari Vasuki ${ }^{2}, K$. Raj Kiran ${ }^{3}$ \\ ${ }^{1}$ Associate Professor, GRIET, Hyderabad, 500090, India \\ ${ }^{2}$ B. Tech, GRIET, Hyderabad, 500090, India \\ ${ }^{3}$ M. Tech, GRIET, Hyderabad, 500090, India
}

\begin{abstract}
Wire electric discharge machining (WEDM) is one amongst the unconventional machining processes which might cut all kinds of shapes with an accuracy of $+/-0.001 \mathrm{~mm}$. It will cut the materials that conduct electricity and can even cut the exotic metals like tungsten carbide, Hastelloy, Inconel etc. In the present work, machining on Inconel 600 by wire EDM with cryogenically treated brass wire is performed. Brass wire of $0.25 \mathrm{~mm}$ diameter has been cryogenically treated at $-90^{\circ} \mathrm{C}, \quad-100^{\circ} \mathrm{C}$ and $-110^{\circ} \mathrm{C}$ temperatures separately. An Experimental layout is designed as per Taguchi's L-9 orthogonal array and experiments were conducted by varying machining parameters viz. Voltage, Pulse ON time and Pulse OFF time. The machining parameters are optimized using Taguchi's methodology for minimum surface roughness and maximum metal removal rate (MRR). A Mathematical regression model for surface roughness and MRR is generated with the help of regression analysis. Through the Analysis of Variance (ANOVA) It was found that for MRR, pulse on time is the foremost contributing factor with $32.69 \%$ and for surface roughness, pulse off time is the foremost contributing factor with $23.59 \%$.
\end{abstract}

\section{INTRODUCTION}

Wire cut electric discharge machining (WEDM) process is one of widely used non-traditional machining process which has the ability to do the machining of complex shaped conductive work piece material. The uniqueness of WEDM process is that it always maintains the gap between the work piece and the wire material [1]. Servo mechanism, Dielectric fluid (de ionized water), wire material, work piece each system plays a key role in maintaining the accuracy in the process. Servo mechanism controls the feed rates, current levels. Dielectric fluid helps in initiating the spark, performs as a coolant and insulator. Spark generated between the work piece and the wire material assists the cutting process [2]. Cryogenic treatment on a wire includes soaking it in liquid nitrogen for few hours with a specific ramp down and ramp up timings [3]. Cryogenic treatment enhances the grain structure of the material thereby improving the electrical conductivity [4]. Shallow cryogenic treatment was chosen over the deep cryogenic because of its advantages over the other type [5]. Selection of wire material and work piece were done on the basis of study on various materials and their properties, Inconel 600 was chosen as the work material because of its applications at cryogenic and elevated temperatures [6]. Brass was chosen as the wire material because of its superior mechanical properties like good electrical conductivity, high melting point. Detail study was done on the Machining parameters, Performance Characteristics, and their effect on each other. Study on Optimization methods like Taguchi method, ANOVA Analysis were also done [7]-[9] The Cryogenic treatment for brass wire was done choosing the conditions based on references [10]. Further Study was done about the process of obtaining the regression model [11] based on the results obtained for MRR and Ra. In-addition to that ANOVA Analysis and Taguchi Optimization was carried out. Inaddition to know the best optimisation various optimisations process are studies[12-16].

In the present work, experiments were planned on a WEDM with cryogenic treated brass wire for the machining of Inconel 600 . The L9 orthogonal array based on design of experiments was applied to plan the experiments, by selecting four controlling factors namely, voltage, pulse ON, Pulse OFF and treatment of the wire The Taguchi analysis is applied to examine how these cutting factors influence the Material removal rate (MRR) and Surface roughness (Ra). An optimal parameter combination was then obtained using the experimental results. Furthermore, analysis of variance (ANOVA) was also carried out to examine the most significant factors for the MRR and Ra in the WEDM process.

\section{EXPERIMENTAL PROCEDURE}

\footnotetext{
* Corresponding author: author@e-mail.org
} 


\subsection{Methodology}

Inconel 600 shown in figure 1 was machined using the cryogenically treated brass wire on the Wire EDM Machine shown in the figure 3. Firstly, the brass wire shown in figure 2 was cryogenically treated at $-90^{\circ} \mathrm{C}$, $100^{\circ} \mathrm{C},-110^{\circ} \mathrm{C}$ and used for machining. Chemical analysis test was done on Inconel 600 and the composition of it was shown in table 1 . Brass wire was procured with $0.25 \mathrm{~mm}$ diameter and Net Weight and diameter of spool $3.50 \mathrm{~kg}$ and $125 \mathrm{~mm}$. The Work material of $31 \mathrm{~mm}$ diameter and Length of $430 \mathrm{~mm}$ and in cylindrical shape. The experiments were conducted by considering the $\mathrm{v}, \mathrm{T}_{\mathrm{on}}, \mathrm{T}_{\text {off }}$, Temperature as the variables. L9 Orthogonal array based on design of experiments with 3 levels and 4 variables shown in table 2. and L9 experimental details shown in table 3. A total of 9 experiments were conducted according to the table of experiments designed.

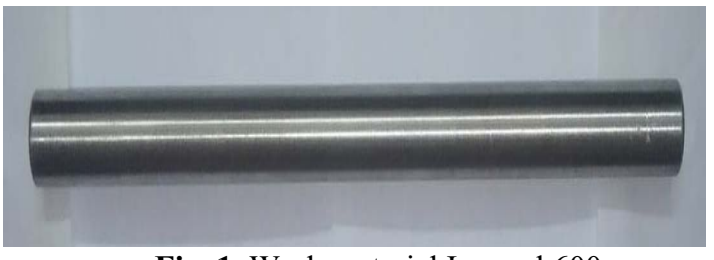

Fig. 1. Work material Inconel 600

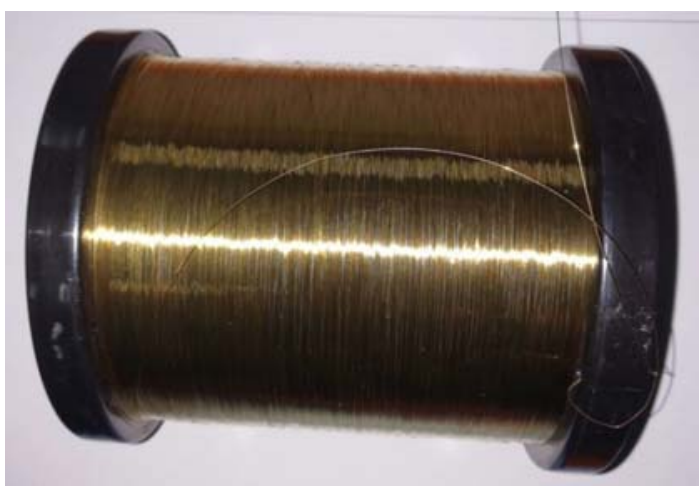

Fig. 2. Brass wire

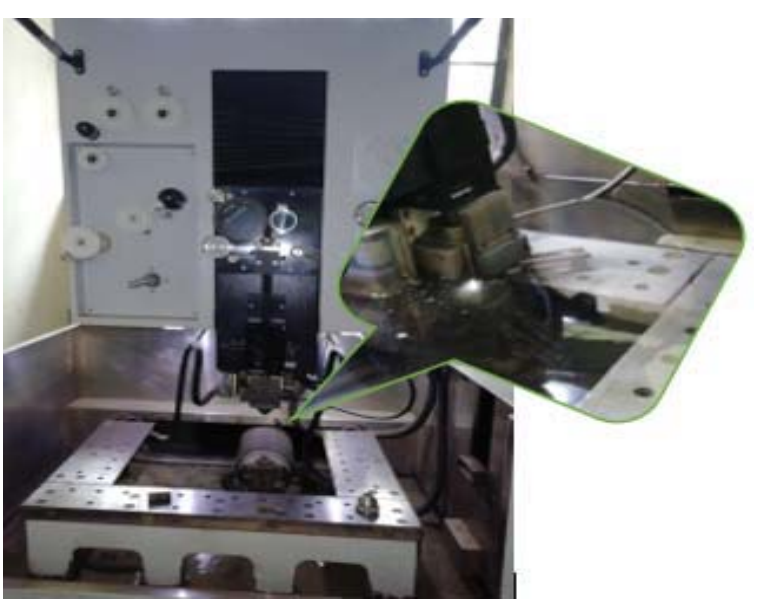

Fig. 3. Experimental setup of Wire EDM Machine

\begin{tabular}{|l|c|}
\hline Elements & Composition (Wt. \%) \\
\hline Carbon & 0.07 \\
\hline Manganese & 0.21 \\
\hline Phosphorus & 0.002 \\
\hline Sulphur & 0.001 \\
\hline Silicon & 0.13 \\
\hline Chromium & 15.48 \\
\hline Copper & 0.02 \\
\hline Titanium & 0.15 \\
\hline Nickel & Remaining \\
\hline
\end{tabular}

Table 2. Machining Parameters and their levels

\begin{tabular}{|c|c|c|c|c|c|}
\hline \multirow{2}{*}{ Parameters } & \multirow{2}{*}{ Units } & \multirow{2}{*}{ Symbol } & \multicolumn{3}{|c|}{ Level } \\
\hline & & & 1 & 2 & 3 \\
\hline Voltage & Volts & $\mathrm{v}$ & 95 & 117 & 140 \\
\hline $\begin{array}{l}\text { Pulse ON } \\
\text { time }\end{array}$ & $\begin{array}{c}\text { Nano } \\
\text { seconds }\end{array}$ & $\mathrm{T}_{\text {on }}$ & 625 & 912 & 1200 \\
\hline $\begin{array}{l}\text { Pulse OFF } \\
\text { time }\end{array}$ & $\begin{array}{c}\text { Micro } \\
\text { seconds }\end{array}$ & $\mathrm{T}_{\text {off }}$ & 26 & 38 & 50 \\
\hline $\begin{array}{l}\text { Cryogenic } \\
\text { Temperature }\end{array}$ & ${ }^{0} \mathrm{C}$ & Temp & -110 & -100 & -90 \\
\hline
\end{tabular}

Table 3. L9 orthogonal array

\begin{tabular}{|c|c|c|c|c|}
\hline SI.No & $\mathbf{V}$ & $\mathbf{T}_{\text {on }}$ & $\mathbf{T}_{\text {off }}$ & ${ }^{\mathbf{0}} \mathbf{C}$ \\
\hline 1 & 95 & 625 & 26 & -110 \\
\hline 2 & 95 & 912 & 38 & -100 \\
\hline 3 & 95 & 1200 & 50 & -90 \\
\hline 4 & 117 & 625 & 38 & -90 \\
\hline 5 & 117 & 912 & 50 & -110 \\
\hline 6 & 117 & 1200 & 26 & -100 \\
\hline 7 & 140 & 625 & 50 & -100 \\
\hline 8 & 140 & 912 & 26 & -90 \\
\hline 9 & 140 & 1200 & 38 & -110 \\
\hline
\end{tabular}

The weights of the work pieces were taken before and after the machining to calculate the Material Removal Rate (MRR). The work pieces after the machining are shown in the Figure 4.MRR is calculated for each work piece by substituting the values of weights before machining, weights after machining, time taken for machining in the given equation 1

$$
M R R=\frac{w_{B \in}-w_{\Omega \complement}}{t} \operatorname{grams} / \mathrm{min}
$$

Where

$\mathrm{W}_{\mathrm{bc}}$ - weight of the material before cut (grams)

$\mathrm{W}_{\mathrm{ac}}$ - weight of the material after cut (grams)

$\mathrm{t}$ - time taken for machining (minutes)

Table 1. Chemical Analysis of Inconel 600 


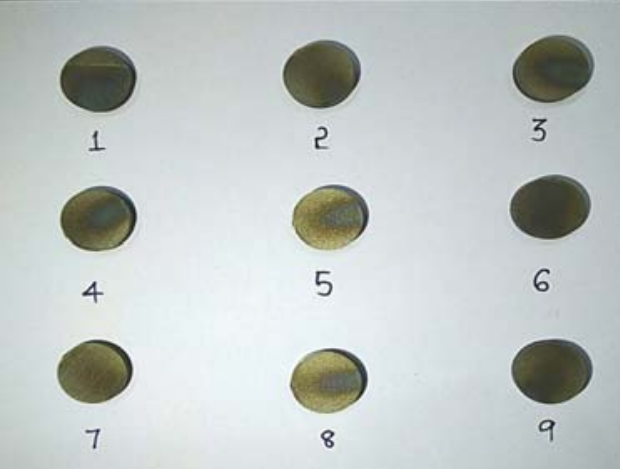

Fig. 4. Work pieces after Machining

Surface Roughness was measured with the Surface finish Tester of Model Surtronic 3+, Rank Taylor Hobson Ltd., made in England. These tests are done in the lab at the temperature $20+/-2^{\circ} \mathrm{C}$.

Table 3. Experimental Result

\begin{tabular}{|c|c|c|c|c|c|c|c|}
\hline Sl.No & $\mathrm{W}_{\mathrm{bc}}$ & $\mathrm{W}_{\mathrm{ac}}$ & $\mathbf{t}$ & MRR & $\mathbf{S} / \mathbf{N}$ & $\mathbf{R a}$ & $\mathbf{S} / \mathbf{N}$ \\
\hline 1 & 115.583 & 94.379 & 11.16 & 1.900 & 5.575 & 2.9 & -9.24 \\
\hline 2 & 115.908 & 94.606 & 11.40 & 1.868 & 5.427 & 3.4 & -10.62 \\
\hline 3 & 118.273 & 97.034 & 9.32 & 2.278 & 7.151 & 4.1 & -12.25 \\
\hline 4 & 118.825 & 97.640 & 12.55 & 1.688 & 4.547 & 2.8 & -8.94 \\
\hline 5 & 118.934 & 97.835 & 10.14 & 2.080 & 6.361 & 3.16 & -9.99 \\
\hline 6 & 118.079 & 96.105 & 9.06 & 2.228 & 6.958 & 3.94 & -11.90 \\
\hline 7 & 118.554 & 97.485 & 9.15 & 2.302 & 7.242 & 3.14 & -9.93 \\
\hline 8 & 119.755 & 97.868 & 13.37 & 1.637 & 4.28 & 3.44 & -10.73 \\
\hline 9 & 118.221 & 98.597 & 10.19 & 1.925 & 5.688 & 3.82 & -11.64 \\
\hline
\end{tabular}

\section{RESULTS AND DISCUSSION}

\subsection{Taguchi Analysis}

Taguchi Analysis was performed in MINITAB19 software. Table 3 shows the experimental results for MRR, $\theta$ and the corresponding $\mathrm{S} / \mathrm{N}$ ratio using Equations (2) and (3). larger the best criteria for MRR and for smaller the best criteria for surface roughness (Ra) was used for calculation of S/N Ratio.

$$
\begin{aligned}
& \frac{g}{\delta}=-10 \log _{10}\left(\frac{\sin }{2} \frac{1}{2}\right) \\
& \frac{\xi}{N}=-10 l o Q_{10}\left(=\lim _{i} y^{2}\right)
\end{aligned}
$$

Since the experimental design is orthogonal, it is then possible to separate out the effect of each cutting parameter at different levels. For example, the mean $\mathrm{S} / \mathrm{N}$ ratio for the cutting speed at levels 1,2 and 3 can be calculated by averaging the $\mathrm{S} / \mathrm{N}$ ratios for the experiments $1-3,4-6$ and 7-9 respectively. The mean
$\mathrm{S} / \mathrm{N}$ ratio for each level of the other cutting parameters can be computed in a similar manner. In addition, the total mean $\mathrm{S} / \mathrm{N}$ ratio for all nine experiments are also calculated and listed in Table 4 and Table 5. Regardless of the lower-the-better or the higher-the-better quality characteristic, the greater the $\mathrm{S} / \mathrm{N}$ ratio corresponds to the smaller variance of the output characteristics around the desired value.

Table 4. Mean of S/N Ratio for MRR

\begin{tabular}{|l|l|l|l|l|}
\hline Level & Voltage & Ton & Toff & Temp \\
\hline 1 & $\mathbf{6 . 0 5 1}$ & 5.788 & 5.605 & 5.875 \\
\hline 2 & 5.956 & 5.357 & 5.221 & $\mathbf{6 . 5 4 3}$ \\
\hline 3 & 5.737 & $\mathbf{6 . 5 9 9}$ & $\mathbf{6 . 9 1 8}$ & 5.326 \\
\hline Delta & 0.314 & 1.243 & 1.697 & 1.216 \\
\hline Rank & 4 & 2 & 1 & 3 \\
\hline
\end{tabular}

From the Table 4, it was found that Voltage at level 1, Ton at level 3, Toff at level 3, Temp at level 2 are the optimum condition in order to obtain the Maximum MRR. From the ranks one can, observe that Toff plays a major role for obtaining the Max MRR and with Ton with rank 2 makes it the second major factor for obtaining the max MRR

Table 5. Mean of S/N Ratio for Ra

\begin{tabular}{|l|l|l|l|l|}
\hline Level & Voltage & Ton & Toff & Temp \\
\hline 1 & -10.71 & $\mathbf{- 9 . 3 7}$ & -10.63 & $\mathbf{- 1 0 . 2 9}$ \\
\hline 2 & $\mathbf{- 1 0 . 2 8}$ & -10.45 & $\mathbf{- 1 0 . 4 1}$ & -10.83 \\
\hline 3 & -10.77 & -11.93 & -10.73 & -10.64 \\
\hline Delta & 0.488 & 2.56 & 0.325 & 0.532 \\
\hline Rank & 3 & 1 & 4 & 2 \\
\hline
\end{tabular}

From the Table 5, it was found that Voltage at level 2, Ton at level 1, Toff at level 2, Temp at level lare the optimum condition in order to obtain the good surface roughness. From the Ranks one can observe that Ton plays a major role for obtaining the good surface roughness and with Temp with rank 2 makes it the second major factor for obtaining the good surface roughness.

\subsection{Mathematical Regression Model}

Regression Equation 4 and 5 for MRR and Ra was obtained with the parameters Voltage, Ton, Toff and Temperature. The obtained Regression equation for MRR, Ra can be used directly to obtain the values of MRR, Ra without the need of performing the 
experiments within the range of parameters selected. From the Model Summary R-sq value obtained for MRR is $96.38 \%$ and for $\mathrm{Ra}$ is $99.11 \%$. This high percentage indicates that values obtained with equation is close to the result obtained.

$$
\begin{aligned}
& \text { MRR }=-0.33+0.0156 \text { Voltage }+0.00503 \text { Ton }-0.162 \\
& \text { Toff }-0.0101 \text { Temp }-0.000063 \text { Voltage*Ton } \\
& +0.001127 \text { Voltage*Toff }+0.000032 \\
& \text { Ton*Toff. }
\end{aligned}
$$

$\mathbf{R a}=4.33+0.0020$ Voltage +0.00503 Ton -0.1886 Toff -0.0085 Temp -0.000042 Voltage*Ton + 0.001079 Voltage*Toff +0.000057 Ton*Toff. (5)

\subsection{ANOVA Analysis}

Table 6 shows the results of ANOVA for MRR. It is found that Pulse ON (Ton) found to be significant parameters affecting MRR.

Table 6 ANOVA Analysis for MRR

\begin{tabular}{|l|l|l|l|l|l|l|}
\hline Source & DF & $\begin{array}{l}\text { Adj } \\
\text { SS }\end{array}$ & $\begin{array}{l}\text { Adj } \\
\text { MS }\end{array}$ & $\begin{array}{l}\text { F- } \\
\text { Value }\end{array}$ & $\begin{array}{l}\text { P- } \\
\text { Value }\end{array}$ & \%C \\
\hline Regression & 7 & 0.470 & 0.067 & 3.81 & 0.376 & - \\
\hline Voltage & 1 & 0.003 & 0.003 & 0.18 & 0.744 & 0.83 \\
\hline Ton & 1 & 0.125 & 0.125 & 7.09 & 0.229 & 32.69 \\
\hline Toff & 1 & 0.055 & 0.055 & 3.14 & 0.327 & 14.49 \\
\hline Temp & 1 & 0.009 & 0.009 & 0.52 & 0.601 & 2.41 \\
\hline $\begin{array}{l}\text { Voltage } \\
\text { *Ton }\end{array}$ & 1 & 0.101 & 0.101 & 5.74 & 0.252 & 26.44 \\
\hline $\begin{array}{l}\text { Voltage } \\
\text { *Toff }\end{array}$ & 1 & 0.056 & 0.056 & 3.22 & 0.324 & 14.84 \\
\hline Ton*Toff & 1 & 0.015 & 0.015 & 0.85 & 0.526 & 3.91 \\
\hline Error & & 0.017 & & - & - & 4.61 \\
\hline Total & & 0.488 & & - & - & 100 \\
\hline
\end{tabular}

Table 7 ANOVA Analysis for Ra

\begin{tabular}{|l|l|l|l|l|l|l|}
\hline Source & DF & Adj SS & $\begin{array}{l}\text { Adj } \\
\text { MS }\end{array}$ & $\begin{array}{l}\text { F- } \\
\text { Value }\end{array}$ & $\begin{array}{l}\text { P- } \\
\text { Value }\end{array}$ & \%C \\
\hline Regression & 7 & 1.678 & 0.239 & 15.84 & 0.191 & - \\
\hline Voltage & 1 & 0.00005 & 0.00005 & 0 & 0.963 & 0.02 \\
\hline Ton & 1 & 0.065 & 0.065 & 4.3 & 0.286 & 21.47 \\
\hline Toff & 1 & 0.071 & 0.071 & 4.72 & 0.275 & 23.59 \\
\hline Temp & 1 & 0.006 & 0.006 & 0.43 & 0.629 & 2.17 \\
\hline $\begin{array}{l}\text { Voltage* } \\
\text { Ton }\end{array}$ & 1 & 0.045 & 0.045 & 3.03 & 0.332 & 15.13 \\
\hline $\begin{array}{l}\text { Voltage* } \\
\text { Toff }\end{array}$ & 1 & 0.052 & 0.052 & 3.44 & 0.315 & 17.19 \\
\hline Ton*Toff & 1 & 0.046 & 0.046 & 3.1 & 0.329 & 15.48 \\
\hline Error & 1 & 0.015 & 0.015 & - & - & 5.00 \\
\hline Total & 8 & 1.693 & - & - & - & 100 \\
\hline
\end{tabular}

Table 7 shows the results of ANOVA for MRR. It is found that Pulse OFF (Toff) found to be significant parameters affecting Ra.

\section{CONCLUSION}

1. It was found that the Optimum condition for Surface roughness with Voltage at level 2 (117 v), Ton at level 1 (625ns), Toff at level 2 (38 $\mu \mathrm{s})$, Temperature at level $1\left(-110^{\circ} \mathrm{C}\right)$

2. It was found that the Optimum condition for Material Removal Rate with Voltage at level 1 $(95 \mathrm{v})$, Ton at level 3 (1200ns), Toff at level 3 $(50 \mu \mathrm{s})$, Temperature at level $2\left(-100^{\circ} \mathrm{C}\right)$

3. The Regression models obtained for Ra, MRR with R-sq $99.11 \%, 96.38 \%$ indicate that the equations obtained are forming a better fit.

4. Through ANOVA Analysis, the most contributing factors for MRR was Pulse ON time with $32.69 \%$.

5. Through ANOVA Analysis, it is found that the most significant factor for Surface Roughness is Pulse OFF time with $23.59 \%$.

\section{REFERENCES}

1. A. S. S. Balan, and A. Giridharan, International Journal of Automotive and Mechanical Engineering, 14, 4097 (2017)

2. . N. Sharma, R. Khanna, and R. Gupta, Procedia Engineering, 64, 710 (2013).

3. J. Kapoor, S. Singh, and J.S. Khamba, Proceedings of the Institution of Mechanical Engineers, Part C: Journal of Mechanical Engineering Science, 226(11), 2750 (2012).

4. K. Satynarayana, K. Rajkiran, and D. Chakradhar, In E3S Web of Conferences EDP Sciences 184, 01067 (2020)

5. J. Kapoor, J. S. Khamba, and S. Singh, International Journal of Materials Engineering Innovation, 3 (3-4), 190 (2012)

6. Y. Gajalappa, A. Krishnaiah, A. B. Kumar,K. K. Saxena, and P.Goyal. Materials Today: Proceedings, 45, 5320 (2021)

7. A. Goswami, J. Kumar, Engineering Science and Technology, an International Journal, 17(4), 236 (2014)

8. B.S. Babu, S. Sathiyaraj, A. K. P. Ramesh, B. A. Afridi, and $\mathrm{K} \mathrm{K}$. Varghese, Materials Today: Proceedings, 45, 6247(2021)

9. D. Marelli, S. K. Singh, S. Nagari, and R. Subbiah, Materials Today: Proceedings, 26,1021(2020)

10. R. Singh, R. P. Singh, M. Tyagi, and R. Kataria, Materials Today: Proceedings, 25, 679 (2020)

11. K. Satyanarayana, M. Mounika, and K. R. Kiran, Materials Today: Proceedings, 44, 2411 (2021). 
12. Lin, Y.C., Wu, F., Wang, Q.-W., Chen, D.-D., Singh, S.K., Vacuum, 151, 283 (2018)

13. Kora, P., Kalva, S.R. Springer Plus, 4 , 19 (2015)

14. Purohit, R., Rana, R.S., Dwivedi, R.K., Banoriya, D., Singh, S.K. Materials Today: Proceedings, 2 ,3378 (2015)

15. Mahalle, G., Salunke, O., Kotkunde, N., Gupta, A.K., Singh, S.K. Journal of Materials Research and Technology, 8, 2130 (2019)

16. Singh, S.K., Dixit, A., Kumar, D.R. International Journal of Advanced Manufacturing Technology, 38, 32 (2008) 